Published in final edited form as:

Curr HIV Res. 2003 July ; 1(3): 275-285.

\title{
HIV-1 Replication and Pathogenesis in the Human Thymus
}

\author{
Eric G. Meissnert,@, Karen M. Duus ${ }^{\dagger, @, ~ R e b e c c a ~ L o o m i s ", @, ~ R h i a n n o n ~ D ' A g o s t i n, @, ~ a n d ~}$ \\ Lishan Sut,\#,@ \\ tDepartment of Microbiology and Immunology, School of Medicine, The University of North \\ Carolina, Chapel Hill, NC 27599-7295, USA \\ \#Curricula in Genetics and Molecular Biology, School of Medicine, The University of North \\ Carolina, Chapel Hill, NC 27599-7295, USA \\ @The Lineberger Comprehensive Cancer Center, School of Medicine, The University of North \\ Carolina, Chapel Hill, NC 27599-7295, USA
}

\begin{abstract}
How HIV replicates and causes destruction of the thymus, and how to restore thymic function, are among the most important questions of HIV-1 pathogenesis and therapy in adult as well as pediatric patients. The thymus appears to function, albeit at reduced levels, throughout the life of adults, to respond to T cell depletion induced by HIV and to be suppressed by HIV. In this review, we summarize recent findings concerning HIV replication and pathogenesis in the human thymus, focusing on mechanistic insights gleaned from studies in the SCID-hu Thy/Liv mouse and human fetal-thymus organ culture (HF-TOC) models. First, we discuss HIV viral determinants and host factors involved in the replication of HIV in the thymus. Second, we consider evidence that both viral factors and host factors contribute to HIV-induced thymocyte depletion. We thus propose that multiple mechanisms, including depletion and suppression of progenitor cells, paracrine and direct lytic depletion of thymocytes, and altered thymocyte selection are involved in HIV-induced pathology in the thymus. With the SCID-hu Thy/Liv mouse and HF-TOC models, it will be important in the coming years to further clarify the virological, cell biological, and immunological mechanisms of HIV replication and pathogenesis in human thymus, and to correlate their significance in HIV disease progression.
\end{abstract}

\section{Keywords}

Thymus; SCID-hu Thy/Liv; HF-TOC; Env; Nef; HIV/AIDS

\section{HIV-1 PATHOGENESIS IN THE THYMUS DURING AIDS PROGRESSION}

The decline of CD4+ T cells in the peripheral circulation is the hallmark of HIV-1 disease progression. A variety of mechanisms have been proposed to account for this loss [77].

\footnotetext{
(C) 2003 Bentham Science Publishers Ltd.

*Address correspondence to this author at the Lineberger Comprehensive Cancer Center, Department of Microbiology and Immunology, School of Medicine, University of North Carolina, Chapel Hill, NC 27599-7295, USA; Tel: 919-966-6654; Fax: 919-966-8212; 1su@med.unc.edu.
} 
Analysis of $\mathrm{T}$ cell phenotypic changes during disease progression indicates that naive $\mathrm{T}$ cells (CD4+ and $\mathrm{CD} 8+$ ) are preferentially depleted, suggesting impairment of mature T cell replenishment [91]. Additionally, a failure to maintain $\mathrm{T}$ cell homeostasis has been correlated with onset of AIDS [74]. It has recently been reported that production of recent thymic emigrants (or naïve T cells) is impaired in HIV-1 infected patients, and suppression of HIV-1 replication with HAART results in a recovery of naïve CD4+ T cells [27]. These findings suggest that $\mathrm{T}$ cell development and replenishment potentials in the thymus may be suppressed by active HIV-1 infection.

The thymus has been shown to be an early site for HIV-1 infection $[23,73]$. In the thymus, CD4 is expressed not only on mature (CD3+CD4+CD8-) T cells but also on less mature (CD3-/+ CD4+CD8+) thymocytes and intrathymic T progenitor (ITTP, CD3-CD4+CD8-) cells $[35,67]$. Though not well studied during HIV-1 infection, thymic organs from HIV-1 infected fetuses and pediatric patients show profound parenchymal damage and involution $[25,42,49,85,87,92,97,100]$. T progenitor cells in the thymus are infected by HIV-1 and their depletion or malfunction may result in thymocyte depletion [96, 107, 110]. AIDS progression is accelerated in HIV-infected infants with abnormal thymus functions [65]. With thymus-mass imaging technologies, it has recently been shown that thymic mass is correlated with production of naïve T cells in HIV+ patients during HAART treatment [78, 101]. Finally, thymus infection and destruction are characteristic of other well characterized lentiviral diseases in rhesus macaques and cats $[8,69]$.

\section{MODELS TO STUDY HIV-1 REPLICATION AND PATHOGENESIS IN THE HUMAN THYMUS}

A number of experimental models have been used to study HIV pathogenesis in the thymus. Although thymus pathology has been investigated in SIV/monkey [69], FIV/cat [8], human/ mouse chimeric organs [39, 113], or transgenic mice [43], these models either lack human thymocytes or human thymus stromal cells, or do not directly study HIV-1. Therefore, this review will focus on studies carried out in SCID-hu Thy/Liv mice and the HF-TOC model.

\section{The SCID-hu Thy/Liv Mouse}

The "SCID-hu Thy/Liv mouse" is constructed by engrafting fragments of human fetal liver and thymus into the immunodeficient C.B-17 scid/scid (SCID) mouse [76, 79]. The resulting "Thy/Liv" organ promotes long-term human T cell differentiation [68, 83]. Normal cell subpopulations (most of them resting) are represented within the organ in expected proportions, a normal TCR V $\beta$ repertoire is displayed [111], and tolerance is induced towards both self major histocompatibility antigens and exogenously-provided superantigens $[112,114]$. The Thy/Liv organ is permissive for infection with primary HIV-1 isolates [82], but not by most tissue culture adapted (and attenuated) isolates such as Lai/ IIIB [109]. HIV infection of the Thy/Liv organ induces thymic involution and thymocyte depletion $[2,17,62,107]$. These events are accompanied by histologic and biochemical evidence of thymocyte apoptosis $[17,107]$ and occur at a more accelerated pace with syncytium-inducing (SI, CXCR4-tropic) viral isolates than with non-syncytium-inducing (NSI, CCR5-tropic) isolates [50]. As observed in the SIV-infected rhesus macaque [54], 
replication of HIV-1 in SCID-hu Thy/Liv mice depends on accessory functions such as Nef, Vpu and Vif $[4,46]$. Therefore, the SCID-hu Thy/Liv mouse provides a relevant in vivo model to study HIV-1 replication and pathogenesis in an intact human hematolymphoid organ. In addition, the SCID-hu Thy/Liv mouse has been used to model hematopoietic stem cell based gene therapy by a number of groups $[1,16,106]$.

\section{The Human Fetal-thymus Organ Culture (HF-TOC) Model}

We and others have also used a human fetal-thymus organ culture (HF-TOC) system that is permissive for HIV infection and exhibits pathology similar to that observed in the SCID-hu Thy/Liv model $[18,28,66,80]$. HF-TOC supports thymus growth for approximately 14 days with normal thymus structure, thymocyte composition, and phenotypes (>70\% CD4+CD8+ DP thymocytes). As in the Thy/Liv organ, the lab-adapted HIV-1 (IIIB or HXB2) fails to replicate in the HF-TOC model. It is possible to produce large numbers (50100 ) of thymus fragments from a single donor. Thus, although there may be diversity between thymus donors and culture conditions that could affect susceptibility to HIV replication and pathogenesis, with inclusion of proper controls there is consistency of donor tissues and environment within each experiment. The HF-TOC model is also readily amenable to biochemical and pharmacological manipulation (Figure 1). For example, HFTOC has been used to assess efficacy of antiviral agents, antibodies, and cytokines [18, 66]. These results indicate that this ex vivo model is useful for the systematic characterization of a variety of virological and biological agents.

\section{HIV-1 REPLICATION IN THE THYMUS}

\section{NSI (R5) vs. SI (X4) HIV-1 Replication in the Thymus}

Based on their coreceptor usage and replication in the MT2 T cell line (CXCR4+), HIV-1 isolates are classified as either nonsyncytium-inducing (NSI, CCR5-tropic), that is associated with early stage of infection, or syncytium-inducing (SI, or CXCR4-tropic) associated with late stage of HIV-1 disease. Sequential viral isolates from patients eventually progressing to AIDS were studied for their ability to replicate and deplete thymocytes in SCID-hu Thy/Liv mice. NSI-R5 isolates obtained during the asymptomatic stage of disease show low levels of replication, while SI-X4 isolates from the same individuals obtained after progression to AIDS replicate rapidly and efficiently in SCID-hu $\mathrm{Th} / \mathrm{Liv}$ mice $[20,50]$.

Consistent with replication studies with primary isolates, X4-tropic HIV clones (e.g., NL4-3) replicates to high levels in the thymus. R5-tropic clones such as BaL replicate very inefficiently, predominantly infecting stromal cells including DC and macrophages [11-14]. To confirm that co-receptor usage is the determinant for replication in the thymus, conversion of NL4-3 from an X4 to an R5 virus with env sequences from BaL [12] or $\mathrm{JRCSF}^{1}$ (L. Su, unpublished results) was associated with altered tropism for cell subpopulations within the Thy/Liv organ, and a slower rate of replication. Therefore, X4tropism seems to be a major determinant of HIV replication in the thymus.

\footnotetext{
${ }^{1} \mathrm{~L}$. Su, unpublished results
} 
Thymocytes at various stages of differentiation express CXCR4 and CCR5 differently [13, $58,59]$. CXCR4 is highly expressed on some hematopoietic progenitor cells and on almost all intrathymic T progenitors (CD3-CD4+CD8- or ITTP) in the thymus. Most DP and CD4+ thymocytes also express high levels of CXCR4. CCR5, however, is undetectable or low on most hematopoietic progenitors, intrathymic T progenitor cells, and thymocytes. As a result, no functional response to CCR-5 agonists was observed with human thymocytes [109, 118]. Therefore, X4-tropic HIV-1 isolates may simply have more target cells allowing for a more substantial and pervasive infection. However, dramatic differences are observed among diverse HIV-1 isolates that share the same pattern of coreceptor usage. For example, R5-tropic isolates from AIDS patients replicate more efficiently than R5 viruses isolated from the same patients before AIDS development [98]. As discussed below, intrinsic determinants of X4-tropic isolates are also involved in HIV replication and pathogenesis in the thymus $[4,46]$. In addition, various cytokines appear to differentially affect replication of X4- or R5-tropic HIV isolates in thymocytes [86].

Other chemokine receptors with potential HIV coreceptor activity are also expressed in the thymus [70, 109]. For example, CCR8 has been suggested to contribute to replication of HIV in the thymus because the CCR8 ligand, I-309, partly suppresses replication of X4, R5 and X4/R5-tropic HIV isolates in the thymus [70].

\section{T Cell Line Adapted (TCLA) vs. Primary HIV-1 Isolates}

Most lab-adapted HIV-1 isolates are attenuated to replicate in primary, resting cells and in the thymus models in vivo. For example, the Lai/IIIB isolate and its associated infectious molecular clones (e.g., HXB2) infect T cell lines (SI and X4-tropic), activated PBMCs in vitro, and even the tonsil histo-culture ex vivo ([37], $\left.{ }^{2}\right)$, but are replication-defective in vivo in the SCID-hu Thy/Liv mouse and ex vivo in HF-TOC $[89,108]$. When a lab worker was accidentally infected by Lai/IIIB, infectious virus was isolated from plasma by coculture with primary PBMC, but not by infection of T cell lines [64, 115]. Replacement of an HXB2 subgenomic fragment encoding the env ORF with the corresponding fragment from the lab worker isolate generates a recombinant virus $(\mathrm{HXB} / \mathrm{LW})$ which replicates in the SCID-hu and HF-TOC models. The specific in vivo replication determinants map to the V1-V3 region of the $\mathrm{HXB} / \mathrm{LW}$ env gene. Interestingly, Nef is not required for $\mathrm{HXB} / \mathrm{LW}$ to replicate efficiently in the thymus.

\section{Macrophage-tropism and Replication in the Thymus}

Multiple cell types, including dendritic cells and macrophages, accompany thymocytes in constituting the thymus. Because most primary HIV-1 isolates (R5, X4, or R5/X4), including $\mathrm{HXB} / \mathrm{LW}$, are able to infect macrophages, this capability could potentially be sufficient to allow for replication in the thymus. Interestingly, specific in vivo replication determinants in the V1-V3 loop region of HXB/LW Env [12, 80, 108] also determine its tropism for replication in monocyte-derived macrophages (MDM). However, a single amino acid in the V3 loop, an early A to T mutation associated with neutralizing antibody resistance [90], was essential for replication of the LW virus in the thymus but not for its

\footnotetext{
${ }^{2}$ Duus and $\mathrm{Su}$, unpublished observation.
} 
ability to infect MDM $[80,108]$. The acquired in vivo replication ability was thus separable from the macrophage-tropism of the in vivo selected LW isolate. In addition, NL4-3 replicates efficiently in the thymus models but does not display macrophage tropism. Together, these studies suggest that Env determinants independent of coreceptor usage and macrophage-tropism are involved in promoting HIV-1 replication in the thymus. The mechanism of Env-mediated HIV replication in the thymus may shed light on our understanding of HIV infection and replication in vivo.

\section{HIV-1 PATHOGENICITY IN THE THYMUS}

\section{Viral Pathogenic Factors in the Destruction of the Thymus}

Mutations of genes including nef or env in SIV and HIV-1 lead to reduced viremia in vivo and decreased disease progression, perhaps as a consequence of the lower viremia $[3,14,42$, $54,89]$. Alterations and deletions in nef from patients have been associated with reduced viral load and long-term non-progression $[26,55,75,95]$. Based on these results, "pathogenic" factors such as Env and Nef may also be considered "replication" factors and may affect pathogenesis indirectly by simply modulating viral loads in vivo. Transgenic mouse models with constitutive expression of Nef in CD4+ T cells and macrophages show CD4+ T cell depletion and other AIDS-like symptoms, suggesting that Nef may be a pathogenic factor [43]. However, the level and timing of transgenic Nef expression are different from HIV-1 infection in humans. In addition, murine host cells may respond differently to HIV-1 Nef proteins. Similarly, it has been reported that ectopic expression of Nef in human CD34+ progenitor cells impairs their T cell development in murine thymus organs [113]. However, the level and timing of transgenic Nef expression are different from HIV-1 infection in humans. In addition, murine host cells may respond differently to HIV-1 Nef proteins. Therefore, whether Nef is a factor for pathogenicity as well as for replication in patients remains unclear.

\section{Separation of Viral Replication and Pathogenesis: Env and Nef as Pathogenic Factors}

Comparison of HIV-1 isolates attenuated in vitro with in vivo-derived pathogenic revertants will help identify important viral determinants for replication and pathogenesis. One example demonstrating that viral factors can mediate pathogenicity is found in the SHIV model (SIV/HIV-env chimeric genome). SHIV variants with enhanced replication and pathogenicity have been isolated from monkeys that were serially infected with nonpathogenic SHIV recombinant viruses [51]. Mutations in the HIV env gene contributed to enhanced replication in monkeys. Interestingly, env determinants have also been defined that specifically contribute to CD4+ T cell depletion (i.e., pathogenicity), but not replication, in monkeys, suggesting that these Envs are intrinsically pathogenic [30].

As discussed above, the specific in vivo replication determinants of $\mathrm{HXB} / \mathrm{LW}$ map to the V1-V3 region of Env. We further demonstrate that $\mathrm{HXB} / \mathrm{LW}$ replicates to high levels in the thymus with no significant thymocyte depletion. Restoration of nef in the recombinant $\mathrm{HXB} / \mathrm{LW}$ genome restores its pathogenic activity with no significant effect on replication [28]. Thus, the replication defect of the attenuated Lai/IIIB isolate can be recovered in vivo by mutations in the env gene without an associated pathogenic phenotype (i.e., the LW env 
protein may have reduced intrinsic pathogenic activity), and Nef can function in the $\mathrm{HXB} / \mathrm{LW}$ clone as a pathogenic factor that does not affect replication in the thymus.

Nef mediates multiple effects on target cells in vitro: it down-regulates CD4 and MHC class I from the infected-cell surface, enhances virion infectivity, and alters multiple $\mathrm{T}$ cell signaling pathways (reviewed in $[23,35,87]$ ). These activities of Nef have been mapped to distinct functional domains of the protein [35]. Different Nef alleles with distinct immunemodulatory activities have recently been reported to correlate with HIV-1 disease progression [22]. However, the in vivo relevance of these different Nef activities remains unclear. In the NL4-3 virus, which requires Nef for optimal replication in the thymus, the ability of Nef to down-regulate CD4 seems to be required for pathogenesis [105]. Because restoration of Nef in the HXB/LW genome restores pathogenic activity without affecting viral replication, this system will be invaluable for dissecting which functional domains of Nef are specifically required for pathogenicity in human thymus and to further examine mechanisms of Nef-mediated pathogenesis in vivo. Our preliminary results suggest that a novel Nef activity, independent of its activities in down-regulating CD4, MHC class I or promoting HIV infectivity, is implicated in thymocyte depletion. ${ }^{3}$ The HXB/LW virus will also be valuable to study mechanisms of HIV-1 env-mediated pathogenesis in thymus.

\section{The Effect of Coreceptor Tropism on Thymus Depletion}

To reiterate the important findings discussed above, it is clear that X4 or SI HIV-1 isolates replicate at higher pace and are more pathogenic in the thymus than R5 or NSI isolates [11, 50], potentially due to the relative size of the susceptible cell populations. It has been demonstrated that the V1-V3 region of Env is a mediator of viral replication and pathogenicity in the thymus $[12,20]$. However, there are differences in the ability to deplete thymocytes within each subset of isolates that share coreceptor usage. Late R5 isolates from AIDS patients are reported to be more pathogenic than earlier R5 isolates from the same patients, suggesting an evolution of viral pathogenicity without a coreceptor change for CXCR4 [98], although the same "pathogenic" R5 isolates are very attenuated in comparison with X4 isolates [14]. Even X4 isolates have demonstrated varying degrees of pathogenicity. The HXB2 clone (derived from Lai/IIIB) is X4 tropic, yet is replication deficient and thus non-pathogenic in the thymus $[80,108]$. The LW12.3 env, when cloned into HXB2 (HXB/LW, X4-tropic), demonstrates high levels of replication, yet it is non-pathogenic [28]. Therefore, although most studies suggest that $\mathrm{X} 4$ or SI isolates are more pathogenic in the thymus, there are distinct exceptions, suggesting that other determinants are involved in HIV-mediated thymocyte depletion.

\section{Mechanisms of HIV-1 Induced Thymus Destruction}

While different viral factors contribute to HIV replication and pathogenesis, the result of pathogenic infection is depletion of thymocytes through mechanisms that remain incompletely determined. Clues to understanding this depletion come from several experimental fronts (Figure 2). First, a profound loss of progenitor cell activity is observed in the context of HIV infection of the thymus [48, 60, 107]. Second, direct lysis of HIV-

${ }^{3}$ D'Agostin R and Su L (2003). The 10th conference on retroviruses and oportunistic infection. Boston. 
infected cells may be involved in thymocyte depletion. Third, death of bystander cells mediated by viral and host pathogenic factors may contribute to depletion. Finally, abnormal $\mathrm{T}$ cell maturation has been reported due to host and viral paracrine factors that mediate perturbation of all thymocytes $[52,53,66]$. We consider each of these scenarios.

\section{Bystander Inhibition of Hematopoietic Progenitor Cell Function in HIV-infected Thymus}

Recent studies using the Thy/Liv model have indicated that colony forming activity of CD34+ HSPC is lost before thymocyte depletion and occurs in the absence of productive infection $[48,60,61]$. Because the colony forming activity was partially recovered upon administration of antiretroviral drugs in parallel with a decrease in viral load, this suggests bystander inhibition of function dependent on viral replication [60, 61].

An attractive mechanism for bystander inhibition of progenitor cells would be perturbation of the stromal environment necessary for proper selection and differentiation of developing thymocytes. Thymic epithelial cells (TECs) in the cortex mediate positive selection of DP $(\mathrm{CD} 4+\mathrm{CD} 8+\mathrm{CD} 3+/-)$ thymocytes, while bone marrow derived macrophages and dendritic cells in the cortical-medullary junctions and medulla help eliminate overly reactive single positive mature thymocytes by negative selection. Interaction between these stromal cells and developing thymocytes is essential for proper thymocyte differentiation, and thus infection and depletion of thymic stromal cells by HIV could have devastating consequences. TECs were shown to endocytose virus and contain viral RNA, although productive infection could not be demonstrated [104]. Interestingly, degenerating TECs were also observed by electron microscopy and immunohistochemistry in the absence of detectable viral RNA [104]. While infection of thymic dendritic cells in culture didn't result in productive infection, virus could be transmitted by coculture with CD4+ T cells, and PDCs are productively infected by HIV in the thymus [54]. Thus, thymic stromal cells (DC, macrophages and TEC) can be infected by HIV and/or are potentially affected as bystanders in the absence of infection. Due to technical limitations, it is not clear whether the HIV-1 infected thymic stromal cells are still functional in supporting long-term de novo human $\mathrm{T}$ cell development, although efficient inhibition of HIV-1 replication in patients can lead to increased production of TREC+ (naïve) T cells [27]. In SCID-hu Thy/Liv mice, HAART treatment leads to transient recovery of thymocyte production although it is not clear whether it is possible to fully and stably restore the function of HIV-depleted thymus organs [116].

\section{Direct Infection and Depletion of ITTP Progenitor Cells by HIV}

Profound depletion of thymocytes could ensue if progenitor cells responsible for regenerating the thymocyte subpopulations are targeted for infection and destruction. Consistent with the observation that some CD34+ progenitor cells express low levels of CD4, a fraction of these progenitors contain HIV DNA after infection in the Thy/Liv model [61]. CD34+ HSPC cells differentiate to common lymphoid progenitor cells (CLP) and intrathymic T progenitor cells (ITTPs) which express CD4 and CXCR4 and are susceptible to efficient infection by X4-tropic isolates [67, 107]. R5-tropic viruses that show slow replication and pathogenesis are also capable of infecting ITTPs, but only late in infection and probably as a result of HIV-induced R5 expression on those cells [11]. 
ITTPs differentiate into immature DP $(\mathrm{CD} 4+\mathrm{CD} 8+\mathrm{CD} 3+/-)$ thymocytes which populate the thymic cortex and account for the majority of lymphocytes present within the fetal and adult thymus [67]. DP thymocytes are transcriptionally active and express high levels of CXCR4, providing fertile ground for HIV infection [58]. DP cells are preferentially depleted in the Thy/Liv, HF-TOC, and SIV models. However, as observed with ITTPs and CD34+ progenitors, infection of DP thymocytes does not necessarily result in cell death. HIV DNA has been observed in CD8+ cells in the periphery, and while transient expression of CD4 during activation could explain susceptibility of these cells to direct infection [56], infection in the thymus of DP cells may occur prior to differentiation. In support of this, infection of DP thymocytes both in vitro and in vivo generates HIV DNA+ CD8 cells [19, 57]. If infection of any of the immature thymocytes does not result in cell death, naïve quiescent CD4+ and CD8+ progeny could harbor latent HIV. Accordingly, activation of naïve single positive cells derived from infected DP cells led to reactivation of HIV gene expression and viral production [19]. Thus, intrathymic T progenitor and immature DP precursors are directly susceptible to infection and depletion, although death does not necessarily follow infection, potentially allowing for latent transmission. The differential ability of R5/NSI and $\mathrm{X} 4 / \mathrm{SI}$ viruses to infect the abundant, immature thymocyte population may explain the greater degree of replication and pathogenesis achieved by X4/SI viruses [11, 12, 20, 50].

\section{Mechanisms of Thymocyte Death: Apoptosis vs. Necrosis}

Extensive depletion of thymocytes is caused by HIV-1 infection of the thymus, yet the mechanism to explain how thymocytes actually die remains incompletely described despite considerable effort. Two important questions remain to be answered. First, how do thymocytes die in response to HIV-1 infection (apoptosis, necrosis, or other)? Second, are all dead or dying thymocytes productively infected with HIV-1 (lytic infection vs. paracrine killing)?

Most thymocytes in a physiological setting die by apoptosis characterized by cell shrinkage, chromosomal condensation, and inter-nucleosomal cleavage of DNA [104]. The majority of DP thymocytes undergo apoptosis by neglect due to lack of TCR expression or its interaction with self MHC, and by induction of apoptosis due to overreactivity between TCR and MHC-self antigens. Because basal expression of the anti-apoptotic Bcl-2 protein is low in DP thymocytes, they seem especially susceptible to apoptosis relative to their more mature single positive progeny. Infection by HIV could presumably hasten or amplify the normal mechanisms responsible for thymocyte death. Alternatively, HIV could directly kill cells via lysis during viral production or by inducing bystander apoptosis.

Early studies performed in the Thy/Liv model indicated that the morphological features of thymocytes in HIV-infected thymuses were consistent with apoptosis, including nuclear condensation and loss of cellular DNA [17]. While DNA fragmentation was observed by TdT-FACS staining, the DNA ladder characteristic of completed apoptosis was not observed in cells from infected implants $[17,50,107]$. Upregulation of Fas/FasL has not been observed in the Thy/Liv model or in the HF-TOC model, although evidence from the SIV macaque model supports apoptotic mechanisms for thymocyte depletion [93]. Infection with SIV results in a slight, but detectable, upregulation of Fas on thymocytes and a more striking 
decrease in both the frequency of Bcl-2 expressing cells and the magnitude of Bcl-2 expression per cell. This correlates with the increase in TdT and Phi Phi Lux (a caspase substrate) staining observed during depletion.

Bergeron et al. address the mechanism of thymocyte death by applying supernatants from infected thymic dendritic cells to purified CD4+ and CD8+ thymocytes and show that cell death ensues without accumulation of trypan blue positive cells, suggesting rapid decimation or engulfment $[7,10]$. Because cyclohexamide incubation inhibits this death, an active apoptotic process rather than passive necrosis is suggested. In support of these findings, blocking Fas and TNFR signaling reduced the extent of cell death, implicating classical apoptotic mediators in these in vitro studies. However, the DNA ladder characteristic of apoptosis was observed neither before nor during thymocyte depletion, again arguing against classical apoptotic induction [7]. In addition, Jameson et. al observed little apoptotic activity at the height of CD4+ cell depletion in the Thy/Liv model [47]. During peak loss of CD4+ thymocytes, with about $10 \%$ of thymocytes productively infected, a high viral DNA load was observed, suggesting that direct lytic killing of thymocytes may be responsible for the rapid depletion. During the latter phases of infection, some apoptosis was observed. It is suggested that direct lysis and necrosis were responsible for initial depletion, followed by a secondary wave of apoptosis due to a perturbed thymic microenvironment and cytokine network late in infection.

Although these studies have attempted to understand how HIV induces thymocyte depletion, the question of how thymocytes actually die remains incompletely answered. While the data alternatively suggest that apoptosis or necrosis may be responsible, variation in the experimental conditions and differences in viral load may contribute to the observed discrepancies [17, 47, 50,107]. An intriguing possibility is that a novel form of cell death may be involved which features characteristics of both apoptosis and necrosis, or "aponecrosis" as characterized by initiation of apoptosis with eventual death by necrosis without completion of the apoptotic cascade [33]. It is possible that the mechanism of HIV induced cell death may vary depending on the strength and nature of the insult as is seen in other cell systems [34].

\section{Mechanisms of Thymocyte Depletion: Direct Lytic Infection vs. Indirect Paracrine Mechanisms}

Both direct and indirect mechanisms are probably involved in HIV-induced thymocyte depletion. Support for the lytic infection model can be found from extensive studies performed in primary CD4+ cells in vitro. Functional envelopes were found to induce cell death by direct necrosis in expressing cells with little bystander depletion [21]. Such a mechanism could presumably be responsible for thymocyte depletion in the context of high viral loads and efficient and extensive infection, although the env gene did not seem to play a major role in the cytolysis of CD4+ T cells in PBMCs [71].

In support of the paracrine hypothesis, the majority of TUNEL positive cells in infected Thy/Liv organs were not infected with HIV, as determined by semiquantitative PCR [107]. The aforementioned bystander inhibition of progenitor cell activity is clearly indicative of paracrine inhibition $[48,60,61]$. Furthermore, in contrast to a linear depletion of thymocytes 
predicted by the direct lytic infection model, a threshold level of HIV replication is required to achieve significant thymocyte depletion [20,107], consistent with aacumulation of paracrine mediators of thymocyte depletion during HIV infection. Furethermore, since CCR5 is expressed on so few cells in the thymus, pathogenesis mediated by R5 tropic viruses obtained from AIDS patients was likely indirect [98]. In addition to the reported induction of IFNa, IL10 and other IFN-inducible factors in the HIV-infected thymus [53, 66], infected thymic dendritic cells in vitro were also shown to produce a heat labile cytotoxic agent capable of killing uninfected thymocytes [7].

A similar bystander phenomenon is observed in the peripheral T cell population in HIV+ patients and in SIV-infected macaques, with gross immune activation and loss of function that cannot be explained by direct infection alone [32]. Lymph nodes from infected patients or macaques show apoptosis primarily in the uninfected bystander population. In the thymus of SIV infected macaques, while the majority of infected cells were observed in the medulla, consistent with CCR5 usage, the greatest number of apoptotic cells (DP thymocytes) were observed in the cortex [93, 117]. Indeed, while viral RNA could be detected in the cortex, viral protein could not, suggesting that the observed apoptosis was predominantly in nonproductively infected thymocytes. Uninfected CD4+ T cells may also be eliminated by interactions with viral or host proteins. HIV infection of target cells leads to formation of multinucleated syncytia with uninfected, CD4+ bystander cells [72, 102]. The formation of syncytia is a direct consequence of interactions of gp120/gp41 with CD4 and the chemokine receptor coreceptors [9]. In addition, cross-linking of CD4 with soluble gp120 followed by CD3 cross-linking has been shown to lead to activation-induced cell death [6, 31, 38]. Induction of FAS and FAS ligand (and TNF/TNFR) has been implicated in the gp120mediated cell death of CD4+ and CD8+ cells [44, 45, 84]. Whether these activities are manifest in the thymus remains unclear, but together these results suggest that paracrine mechanisms may contribute to HIV-1 pathogenesis in the thymus.

A potential source of paracrine factors is viral proteins. Soluble viral proteins (Env or virions) alone or in the context of defective virions are detectable in the serum of HIV+ patients, and many of these proteins could act as paracrine factors to induce cell signaling or death. Because the role of viral proteins in induction of thymocyte cell death has not been extensively examined, we refer the reader to a review of mechanisms by which viral proteins mediate apoptosis in peripheral lymphocytes [31]. Of the 9 HIV encoded proteins, Env and Nef have received the most attention in the context of pathogenesis. While Env has been proposed to act as a superantigen in the context of thymic selection, analysis of TCR diversity in the Thy/Liv model has indicated random loss of $\mathrm{V} \beta$ repertoire due to thymocyte depletion rather than restricted $\mathrm{V} \beta$ loss indicative of a superantigen like effect [15, 63]. Indeed, these results are consistent with a role of HIV in perturbing T cell development through immature thymocyte depletion. Application of recombinant viral proteins in HFTOC will help determine their potential role in hastening paracrine death of thymocytes.

In accordance with the results showing upregulation of IFNa associated genes, MHC class I is upregulated on all thymocytes, particularly DP thymocytes, during infection in both the Thy/Liv and HF-TOC models [68]. IFNa secretion by type 2 predendritic cells (pDC2 or PDC) upon infection was recently demonstrated in HF-TOC $[53,66]$. Though IFNa was 
able to prevent infection by NL4-3 when added exogenously, endogenous production was insufficient to control viral replication and pathogenesis. Because ITTPs and DP cells express the highest levels of IFNa receptors, they may be particularly susceptible to this mechanism of paracrine modulation alone or in combination with other viral or host pathogenic factors [53].

MHCI upregulation has also been observed on thymic stromal cells, which may result in abnormal selection of thymocytes. DP thymocytes themselves can also participate in negative selection, suggesting that upregulation of MHCI may have detrimental consequences for their brethren in accordance with the avidity model of selection. Indeed, $\mathrm{CD} 8{ }^{\mathrm{lo}} \mathrm{CD}^{+} \mathrm{SP}$ thymocytes are generated in HIV-depleted thymus organs [54].

\section{PERSPECTIVES}

Studies of HIV replication and pathogenesis using the thymus models have greatly advanced our understanding while leaving many of the original questions regarding mechanism of pathogenesis unresolved. First, we must continue to identify viral determinants and host mediators of replication and pathogenesis. While cell tropism and accompanying replication levels tend to correlate with pathogenesis, the $\mathrm{X} 4$ tropic virus $\mathrm{HXB} / \mathrm{LW}$ can replicate to high levels in HF-TOC without causing significant thymocyte depletion. Therefore other intrinsic properties of different HIV isolates and the response of the host must contribute to pathogenesis. Through viral genetics using replication competent, pathogenicity defective viruses like $\mathrm{HXB} / \mathrm{LW}$, we can define the pathogenic determinants of the virus essential for thymocyte depletion. Application of recombinant viral proteins, such as conformationallysound Env within AT-2-inactivated virions [31,94] or reconstituted in liposomes [41], to HF-TOC will also facilitate dissection of viral determinants. This analysis can be extended to assess the contribution of other viral products aside from Nef and Env on cytokine secretion and cell function in the microenvironment of the thymus using recombinant proteins.

Second, while several host factors appear to be involved in paracrine perturbation of thymic function, many undoubtedly remain to be discovered. Which host factors induced by HIV infection in the thymus contribute to cell death? Applying proteomics to compare proteins expressed in thymuses infected with the nonpathogenic HXB/LW virus or a pathogenic virus should help identify these factors. The utility of the HF-TOC model, which allows for the addition of components such as blocking antibodies or cytokines directly to the culture media, will help verify any identified factors.

Third, much work remains to be done to determine the precise mechanism of thymocyte cell death. While necrosis and apoptosis both appear to contribute, the specific signaling pathways which are responsible remain largely uncharacterized. By applying specific inhibitors of cell death and signaling pathways in HF-TOC, we can begin to address this issue. Additionally, using technology allowing for production of conformationally reliable proteins such as envelope, we can begin to dissect their effect on signaling outside of the context of the complicated viral infection. 
Fourth, suppressor or regulatory $\mathrm{T}$ cells have reemerged as immune modulators capable of negatively regulating a variety of responses through either cell/cell contact or through the secretion of soluble mediators (reviewed in [100]). From 5-10\% of human CD4+ SP thymocytes are CD4+CD25+ with characteristics of a regulatory cell population, characterized by CTLA4, TNFR2, and CCR8 expression, lack of proliferation and cytokine secretion after stimulation through CD3, and ability to inhibit the proliferation of CD4+CD25- cells after CD3 stimulation by modulating IL-2 production in a cell contact dependent manner that utilizes CTLA4 and TGF $\beta$ [5]. Does HIV infection of the thymus result in preferential depletion or sparing of these cells relative to normal $\alpha \beta C D 4+$ thymocytes? Does perturbation of the stromal environment by R5 or X4 tropic viruses affect development of $\mathrm{CD} 4+\mathrm{CD} 25+\mathrm{T}$ cells which could contribute to the anergy observed in the periphery of HIV-infected patients? We and others have observed increased production of IL-10 and type 1 interferons in the HIV-infected thymus [53, 66], which in the context of normal thymic TCR stimulation could potentially affect the production of T regulatory cells. The SCID-hu Thy/Liv mouse and HF-TOC models are amenable to initially address these hypotheses.

Finally, many questions about thymic function, particularly regarding stromal cells, remain unresolved. Are infected stromal cells capable of supporting normal selection and differentiation of thymocytes? Are thymocytes that traverse an HIV-infected thymus normal in function or do they show increased susceptibility to anergy or deletion in the periphery? For example, MHC class I upregulation leads to selection of CD8 mature single positive thymocytes with lower expression of CD8 to allow escape from negative selection, which could result in increased threshold for activation in the periphery and predisposition to anergy [52]. Efforts to improve the current SCID-hu Thy/Liv or HF-TOC model to allow for analysis of experimentally altered stromal cells as well as thymocytes would facilitate the study of these questions.

\section{References}

1. Akkina RK, Rosenblatt JD, Campbell AG, Chen IS, Zack JA. Blood. 1994; 84:1393-1398. [PubMed: 7520766]

2. Aldrovandi GM, Feuer G, Gao L, Jamieson B, Kristeva M, Chen IS, Zack JA. Nature. 1993; 363:732-736. [PubMed: 8515816]

3. Aldrovandi GM, Gao L, Bristol G, Zack JA. Journal of Virology. 1998; 72:7032-7039. [PubMed: 9696795]

4. Aldrovandi GM, Zack JA. Journal of Virology. 1996; 70:1505-1511. [PubMed: 8627668]

5. Annunziato F, Cosmi L, Liotta F, Lazzeri E, Manetti R, Vanini V, Romagnani P, Maggi E, Romagnani S. Journal of Experimental Medicine. 2002; 196:379-387. [PubMed: 12163566]

6. Banda NK, Bernier J, Kurahara DK, Kurrle R, Haigwood N, Sekaly RP, Finkel TH. Journal of Experimental Medicine. 1992; 176:1099-1106. [PubMed: 1402655]

7. Beaulieu S, Lafontaine M, Richer M, Courchesne I, Cohen EA, Bergeron D. Virology. 1998; 241:285-297. [PubMed: 9499803]

8. Beebe AM, Dua N, Faith TG, Moore PF, Pedersen NC, Dandekar S. Journal of Virology. 1994; 68:3080-3091. [PubMed: 8151773]

9. Berger EA, Murphy PM, Farber JM. Annual Review of Immunology. 1999; 17:657-700.

10. Bergeron D, Beaulieu S, Lafontaine M, Courchesne I, Cohen EA. Advances in Experimental Medical Biology. 1997; 417:433-438. 
11. Berkowitz RD, Alexander S, Bare C, Linquist-Stepps V, Bogan M, Moreno ME, Gibson L, Wieder ED, Kosek J, Stoddart CA, McCune JM. Journal of Virology. 1998; 72:10108-10117. [PubMed: 9811751]

12. Berkowitz RD, Alexander S, McCune JM. AIDS Research and Human Retroviruses. 2000; 16:1039-1045. [PubMed: 10933618]

13. Berkowitz RD, Beckerman KP, Schall TJ, McCune JM. Journal of Immunology. 1998; 161:3702_ 3710 .

14. Berkowitz RD, van't Wout AB, Kootstra NA, Moreno ME, Linquist-Stepps VD, Bare C, Stoddart CA, Schuitemaker H, McCune JM. Journal of Virology. 1999; 73:7817-7822. [PubMed: 10438873]

15. Boldt-Houle DM, Jamieson BD, Aldrovandi GM, Rinaldo CR Jr, Ehrlich GD, Zack JA. AIDS Res Human Retroviruses. 1997; 13:125-134. [PubMed: 9007198]

16. Bonyhadi ML, Moss K, Voytovich A, Auten J, Kalfoglou C, Plavec I, Forestell S, Su L, Bohnlein E, Kaneshima H. Journal of Virology. 1997; 71:4707-4716. [PubMed: 9151864]

17. Bonyhadi ML, Rabin L, Salimi S, Brown DA, Kosek J, McCune JM, Kaneshima H. Nature. 1993; 363:728-732. [PubMed: 8100043]

18. Bonyhadi ML, Su L, Auten J, McCune JM, Kaneshima H. AIDS Res Hum Retroviruses. 1995; 11:1073-1080. [PubMed: 8554904]

19. Brooks DG, Kitchen SG, Kitchen CM, Scripture-Adams DD, Zack JA. Nature Medicine. 2001; 7:459-464.

20. Camerini D, Su HP, Gamez-Torre G, Johnson ML, Zack JA, Chen IS. Journal of Virology. 2000; 74:3196-3204. [PubMed: 10708436]

21. Cao J, Park IW, Cooper A, Sodroski J. Journal of Virology. 1996; 70:1340-1354. [PubMed: 8627650]

22. Carl S, Greenough TC, Krumbiegel M, Greenberg M, Skowronski J, Sullivan JL, Kirchhoff F. Journal of Virology. 2001; 75:3657-3665. [PubMed: 11264355]

23. Courgnaud V, Laure F, Brossard A, Bignozzi C, Goudeau A, Barin F, Brechot C. AIDS Research and Human Retroviruses. 1991; 7:337-341. [PubMed: 2064830]

24. Cullen BR. Cell. 1998; 93:685-692. [PubMed: 9630214]

25. Davis AEJ. Annals of the New York Academy of Sciences. 1984; 437:493-502. [PubMed: 6598313]

26. Deacon NJ, Tsykin A, Solomon A, Smith K, Ludford-Menting M, Hooker DJ, McPhee DA, Greenway AL, Ellett A, Chatfield C, et al. Science. 1995; 270:988-991. [PubMed: 7481804]

27. Douek DC, McFarland RD, Keiser PH, Gage EA, Massey JM, Haynes BF, Polis MA, Haase AT, Feinberg MB, Sullivan JL, Jamieson BD, Zack JA, Picker LJ, Koup RA. Nature. 1998; 396:690695. [PubMed: 9872319]

28. Duus KM, Miller ED, Smith JA, Kovalev GI, Su L. Journal of Virology. 2001; 75:3916-3924. [PubMed: 11264380]

29. Esser MT, Bess JW Jr, Suryanarayana K, Chertova E, Marti D, Carrington M, Arthur LO, Lifson JD. Journal of Virology. 2001; 75:1152-1164. [PubMed: 11152488]

30. Etemad-Moghadam B, Sun Y, Nicholson EK, Fernandes M, Liou K, Gomila R, Lee J, Sodroski J. Journal of Virology. 2000; 74:4433-4440. [PubMed: 10756060]

31. Finkel TH, Banda NK. Current Opinions in Immunology. 1994; 6:605-615.

32. Finkel TH, Tudor-Williams G, Banda NK, Cotton MF, Curiel T, Monks C, Baba TW, Ruprecht RM, Kupfer A. Nature Medicine. 1995; 1:129-134.

33. Formigli L, Papucci L, Tani A, Schiavone N, Tempestini A, Orlandini GE, Capaccioli S, Orlandini SZ. Journal of Cellular Physiology. 2000; 182:41-49. [PubMed: 10567915]

34. Formigli L, Zecchi Orlandini S, Capaccioli S, Poupon MF, Bani D. Cells, Tissues, Organs. 2002; 170:99-110. [PubMed: 11731699]

35. Galy A, Verma S, Barcena A, Spits H. Journal of Experimental Medicine. 1993; 178:391-401. [PubMed: 7688021]

36. Geyer M, Fackler OT, Peterlin BM. EMBO Rep. 2001; 2:580-585. [PubMed: 11463741]

Curr HIV Res. Author manuscript; available in PMC 2015 May 08. 
37. Glushakova S, Grivel JC, Fitzgerald W, Sylwester A, Zimmerberg J, Margolis LB. Nature Medicine. 1998; 4:346-349.

38. Gougeon ML, Laurent CA, Hovanessian AG, Montagnier L. Seminars in Immunology. 1993; 5:187-194. [PubMed: 8102263]

39. Greiner DL, Shultz LD, Deluca D, Leif JH, Christianson SW, Hesselton RM. In Vivo. 1996; 10:33-37. [PubMed: 8726809]

40. Grody W, Fligiel S, Naeim F. American Journal of Clinical Pathology. 1985; 84:85-95. [PubMed: 4014079]

41. Grundner C, Mirzabekov T, Sodroski J, Wyatt R. Journal of Virology. 2002; 76:3511-3521. [PubMed: 11884575]

42. Hahn BH, Shaw GM, Arya SK, Popovic M, Gallo RC, Wong SF. Nature. 1984; 312:166-169. [PubMed: 6095086]

43. Hanna Z, Kay DG, Rebai N, Guimond A, Jothy S, Jolicoeur P. Cell. 1998; 95:163-175. [PubMed: 9790524]

44. Herbein G, Mahlknecht U, Batliwalla F, Gregersen P, Pappas T, Butler J, O’Brien WA, Verdin E. Nature. 1998; 395:189-194. [PubMed: 9744279]

45. Herbein G, Van Lint C, Lovett JL, Verdin E. Journal of Virology. 1998; 72:660-670. [PubMed: 9420271]

46. Jamieson BD, Aldrovandi GM, Planelles V, Jowett JB, Gao L, Bloch LM, Chen IS, Zack JA. Journal of Virology. 1994; 68:3478-3485. [PubMed: 8189487]

47. Jamieson BD, Uittenbogaart CH, Schmid I, Zack JA. Journal of Virology. 1997; 71:8245-8253. [PubMed: 9343176]

48. Jenkins M, Hanley MB, Moreno MB, Wieder E, McCune JM. Blood. 1998; 91:2672-2678. [PubMed: 9531575]

49. Joshi V, Oleske Jm. Archives of Pathology \& Laboratory Medicine. 1985; 109:142-146. [PubMed: 3838438]

50. Kaneshima H, Su L, Bonyhadi ML, Connor RI, Ho DD, McCune JM. Journal of Virology. 1994; 68:8188-8192. [PubMed: 7966610]

51. Karlsson GB, Halloran M, Li J, Park IW, Gomila R, Reimann KA, Axthelm MK, Iliff SA, Letvin L, Sodroski J. Journal of Virology. 1997; 71:4218-4225. [PubMed: 9151808]

52. Keir ME, Rosenberg MG, Sandberg JK, Jordan KA, Wiznia A, Nixon DF, Stoddart CA, McCune JM. Journal of Immunology. 2002; 169:2788-2796.

53. Keir ME, Stoddart CA, Linquist-Stepps V, Moreno ME, McCune JM. Journal of Immunology. 2002; 168:325-331.

54. Kestler, Hd; Ringler, DJ.; Mori, K.; Panicali, DL.; Sehgal, PK.; Daniel, MD.; Desrosiers, RC. Cell. 1991; 65:651-662. [PubMed: 2032289]

55. Kirchhoff F, Easterbrook PJ, Douglas N, Troop M, Greenough TC, Weber J, Carl S, Sullivan JL, Daniels RS. Journal of Virology. 1999; 73:5497-5508. [PubMed: 10364298]

56. Kitchen SG, LaForge S, Patel VP, Kitchen CM, Miceli MC, Zack JA. Blood. 2002; 99:207-212. [PubMed: 11756173]

57. Kitchen SG, Uittenbogaart CH, Zack JA. J Virol. 1997; 71:5713-5722. [PubMed: 9223457]

58. Kitchen SG, Zack JA. Journal of Virology. 1997; 71:6928-6934. [PubMed: 9261420]

59. Kitchen SG, Zack JA. AIDS Research and Human Retroviruses. 1999; 15:143-148. [PubMed: 10029246]

60. Koka PS, Fraser JK, Bryson Y, Bristol GC, Aldrovandi GM, Daar ES, Zack JA. Journal of Virology. 1998; 72:5121-5127. [PubMed: 9573283]

61. Koka PS, Jamieson BD, Brooks DG, Zack JA. Journal of Virology. 1999; 73:9089-9097. [PubMed: 10516015]

62. Kollmann TR, Kim A, Pettoello MM, Hachamovitch M, Rubinstein A, Goldstein MM, Goldstein H. Journal of Immunology. 1995; 154:907-921.

63. Komanduri KV, Salha MD, Sekaly RP, McCune JM. Journal of Immunology. 1997; 158:544-549.

Curr HIV Res. Author manuscript; available in PMC 2015 May 08. 
64. Kong LI, Taylor ME, Waters D, Blattner WA, Hahn BH, Shaw GM. International Conference on AIDS. 1989; 5:518.

65. Kourtis AP, Ibegbu C, Nahmias AJ, Lee FK, Clark WS, Sawyer MK, Nesheim S. New England Journal of Medicine. 1996; 335:1431-1436. [PubMed: 8875920]

66. Kovalev G, Duus K, Wang L, Lee R, Bonyhadi M, Ho D, McCune JM, Kaneshima H, Su L. Journal of Immunology. 1999; 162:7555-7562.

67. Kraft DL, Weissman IL, Waller EK. Journal of Experimental Medicine. 1993; 178:265-277. [PubMed: 8315382]

68. Krowka JF, Sarin S, Namikawa R, McCune JM, Kaneshima H. Journal of Immunology. 1991; 146:3751-3756.

69. Lackner AA, Vogel P, Ramos RA, Kluge JD, Marthas M. American Journal of Pathology. 1994; 145:428-439. [PubMed: 8053500]

70. Lee S, Tiffany HL, King L, Murphy PM, Golding H, Zaitseva MB. Journal of Virology. 2000; 74:6946-6952. [PubMed: 10888633]

71. Lenardo MJ, Angleman SB, Bounkeua V, Dimas J, Duvall MG, Graubard MB, Hornung F, Selkirk MC, Speirs CK, Trageser C, Orenstein JO, Bolton DL. Journal of Virology. 2002; 76:5082-5093. [PubMed: 11967324]

72. Lifson JD, Reyes GR, McGrath MS, Stein BS, Engleman EG. Science. 1986; 232:1123-1127. [PubMed: 3010463]

73. Mano H, Chermann J. AIDS Res Human Retroviruses. 1991; 7:83-88. [PubMed: 2015116]

74. Margolick JB, Munoz A, Donnenberg AD, Park L, Galai N, Giorgi J, O’Gorman M, Ferbas J. Nature Medicine. 1995; 1:674-680.

75. Mariani R, Kirchhoff F, Greenough TC, Sullivan JL, Desrosiers RC, Skowronski J. Journal of Virology. 1996; 70:7752-7764. [PubMed: 8892896]

76. McCune JM. Bone Marrow Transplantation. 1992; 1:74-76. [PubMed: 1354528]

77. McCune JM. Nature. 2001; 410:974-979. [PubMed: 11309627]

78. McCune JM, Loftus R, Schmidt DK, Carroll P, Webster D, Swor-Yim LB, Francis IR, Gross BH, Grant RM. Journal of Clinical Investigation. 1998; 101:2301-2308. [PubMed: 9616201]

79. McCune JM, Namikawa R, Kaneshima H, Shultz LD, Lieberman M, Weissman IL. Science. 1988; 241:1632-1639. [PubMed: 2971269]

80. Miller ED, Duus KM, Townsend M, Yi Y, Collman R, Reitz M, Su L. Journal of Virology. 2001; 75:8498-8506. [PubMed: 11507195]

81. Miller ED, Smith JA, Lightinger M, Wang L, Su L. AIDS. 2003 In Press.

82. Namikawa R, Kaneshima H, Lieberman M, Weissman IL, Mc Cune JM. Science. 1988; 242:16841686. [PubMed: 3201256]

83. Namikawa R, Weilbaecher KN, Kaneshima H, Yee EJ, McCune JM. Journal of Experimental Medicine. 1990; 172:1055-1063. [PubMed: 2212942]

84. Oyaizu N, McCloskey TW, Than S, Pahwa S. Blood. 1996; 87:2361-2368. [PubMed: 8630399]

85. Papiernik M, Brossard Y, Mulliez N, Roume J, Brechot C, Barin F, Goudeau A, Bach J, Griscelli C, Henrion R, et al. Pediatrics. 1992; 89:297-301. [PubMed: 1734399]

86. Pedroza-Martins L, Boscardin WJ, Anisman-Posner DJ, Schols D, Bryson YJ, Uittenbogaart CH. Journal of Virology. 2002; 76:6929-6943. [PubMed: 12072494]

87. Pekovic DD, Gornitsky M, Ajdukovic D, Dupuy JM, Chausseau JP, Michaud J, Lapointe N, Gilmore N, Tsoukas C, Zwadlo G, et al. Journal of Pathology. 1987; 152:31-35. [PubMed: 3305846]

88. Peter F. Immunity. 1998; 9:433-437. [PubMed: 9806629]

89. Popovic M, Sarngadharan MG, Read E, Gallo RC. Science. 1984; 224:497-500. [PubMed: 6200935]

90. Reitz MS, Hall L, Robert GM, Lautenberger J, Hahn BM, Shaw GM, Kong LI, Weiss SH, Waters D, Gallo RC. AIDS Research and Human Retroviruses. 1994; 10:1143-1155. [PubMed: 7826699]

91. Roederer M, Dubs JG, Anderson MT, Raju PA, Herzenberg LA, Herzenberg LA. Journal of Clinical Investigation. 1995; 95:2061-2066. [PubMed: 7738173] 
92. Rosenzweig M, Clark DP, Gaulton GN. 1993; 7:1601-1605.

93. Rosenzweig M, Connole M, Forand-Barabasz A, Tremblay MP, Johnson RP, Lackner AA. Journal of Immunology. 2000; 165:3461-3468.

94. Rossio JL, Esser MT, Suryanarayana K, Schneider DK, Bess JW Jr, Vasquez GM, Wiltrout TA, Chertova E, Grimes MK, Sattentau Q, Arthur LO, Henderson LE, Lifson JD. Journal of Virology. 1998; 72:7992-8001. [PubMed: 9733838]

95. Salvi R, Garbuglia AR, Di Caro A, Pulciani S, Montella F, Benedetto A. Journal of Virology. 1998; 72:3646-3657. [PubMed: 9557645]

96. Schnittman SM, Denning SM, Greenhouse JJ, Justement JS, Baseler M, Kurtzberg J, Haynes BF, Fauci AS. Proceedings of the National Academy of Sciences, USA. 1990; 87:7727-7731.

97. Schuurman H, Krone Wj, Broekhuizen R, van Baarlen J, van Veen P, Golstein Al, Huber J, Goudsmit J. American Journal of Pathology. 1989; 134:1329-1338. [PubMed: 2474255]

98. Scoggins RM, Taylor JR Jr, Patrie J, van't Wout AB, Schuitemaker H, Camerini D. Journal of Virology. 2000; 74:3205-3216. [PubMed: 10708437]

99. Seemayer TA, Laroche AC, Russo P, Malebranche R, Arnoux E, Guerin J-M, Pierre G, Dupuy JM, Gartner JG, Lapp WS, Spira TJ, Elie R. Human Pathology. 1984; 15:469-474. [PubMed: 6609873]

100. Shevach EM. Nature Reviews Immunology. 2002; 2:389-400.

101. Smith KY, Valdez H, Landay A, Spritzler J, Kessler HA, Connick E, Kuritzkes D, Gross B, Francis I, McCune JM, Lederman MM. Journal of Infectious Diseases. 2000; 181:141-147. [PubMed: 10608760]

102. Sodroski J, Goh WC, Rosen C, Campbell K, Haseltine WA. Nature. 1986; 322:470-474. [PubMed: 3016552]

103. Spits H. Nature Reviews Immunology. 2002; 2:760-772.

104. Stanley SK, McCune JM, Kaneshima H, Justement JS, Sullivan M, Boone E, Baseler M, Adelsberger J, Bonyhadi M, Orenstein J, Fox CH, Fauci AS. Journal of Experimental Medicine. 1993; 178:1151-1163. [PubMed: 8376927]

105. Stoddart CA, Geleziunas R, Ferrell S, Linquist-Stepps V, Moreno ME, Bare C, Xu W, Yonemoto W, Bresnahan PA, McCune JM, Greene WC. Journal of Virology. 2003; 77:2124-2133. [PubMed: 12525647]

106. Su L. Reviews in Medical Virology. 1997; 7:157-166. [PubMed: 10398480]

107. Su L, Kaneshima H, Bonyhadi M, Salimi S, Kraft D, Rabin L, McCune JM. Immunity. 1995; 2:25-36. [PubMed: 7600300]

108. Su L, Kaneshima H, Bonyhadi ML, Lee R, Auten J, Wolf A, Du B, Rabin L, Hahn BH, Terwilliger E, McCune JM. Virology. 1997; 227:45-52. [PubMed: 9007057]

109. Taylor JR Jr, Kimbrell KC, Scoggins R, Delaney M, Wu L, Camerini D. Journal of Virology. 2001; 75:8752-8760. [PubMed: 11507220]

110. Valentin H, Nugeyre M, Vuillier F, Boumsell L, Schmid M, Barre-Sinoussi F, Pereira R. Journal of Virology. 1994; 68:3041-3050. [PubMed: 7512158]

111. Vandekerckhove BA, Baccala R, Jones D, Kono DH, Theofilopoulos AN, Roncarolo MG. Journal of Experimental Medicine. 1992; 176:1619-1624. [PubMed: 1460421]

112. Vandekerckhove BA, Namikawa R, Bacchetta R, Roncarolo MG. Journal of Experimental Medicine. 1992; 175:1033-1043. [PubMed: 1348080]

113. Verhasselt B, Naessens E, Verhofstede C, De Smedt M, Schollen S, Kerre T, Vanhecke D, Plum J. Blood. 1999; 94:2809-2818. [PubMed: 10515884]

114. Waller EK, Sen MA, Kamel OW, Hansteen GA, Schick MR, Weissman IL. Blood. 1992; 80:3144-3156. [PubMed: 1467521]

115. Weiss SH, Goedert JJ, Gartner S, Popovic M, Waters D, Markham P, di Marzo Veronese F, Gail MH, Barkley WE, Gibbons J, Gill F, Leuther M, Shaw GM, Gallo RC, Blattner WA. Science. 1988; 239:68-71. [PubMed: 3336776]

116. Withers-Ward ES, Amado RG, Koka PS, Jamieson BD, Kaplan AH, Chen IS, Zack JA. Nature Medicine. 1997; 3:1102-1109. 
117. Wykrzykowska JJ, Rosenzweig M, Veazey RS, Simon MA, Halvorsen K, Desrosiers RC, Johnson RP, Lackner AA. Journal of Experimental Medicine. 1998; 187:1767-1778. [PubMed: 9607918]

118. Zamarchi R, Allavena P, Borsetti A, Stievano L, Tosello V, Marcato N, Esposito G, Roni V, Paganin C, Bianchi G, Titti F, Verani P, Gerosa G, Amadori A. Clinical and Experimental Immunology. 2002; 127:321-330. [PubMed: 11876757] 

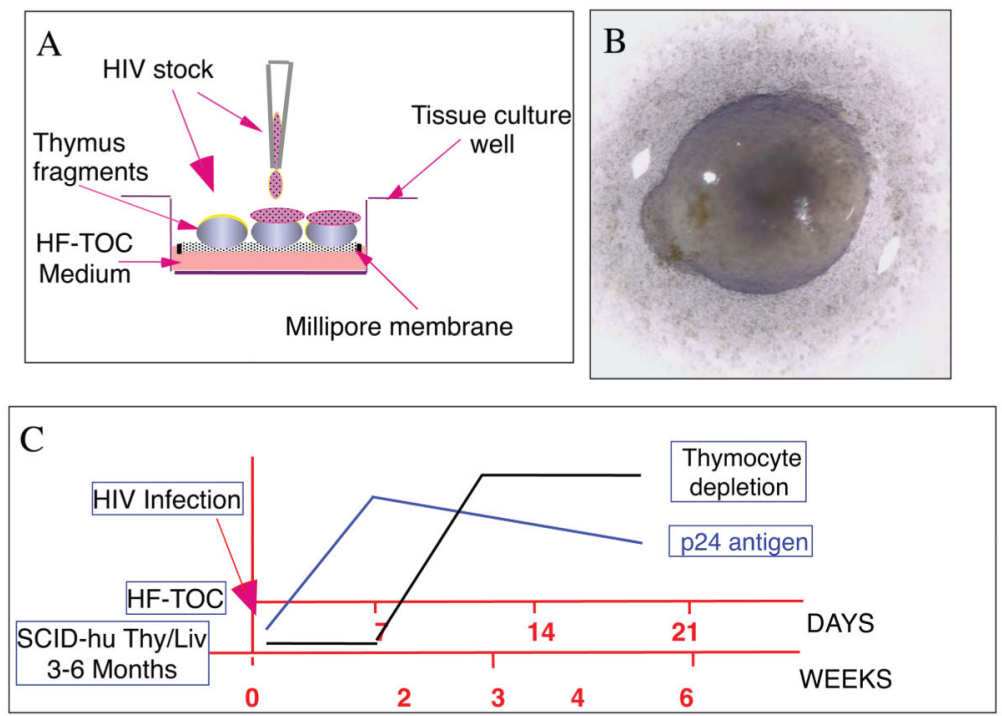

Fig. (1). HIV-1 replication and pathogenesis in the human fetal thymus organ culture (HF-TOC) model and the SCID-hu Thy/Liv mouse

A. Human fetal thymus fragments containing about 4 intact thymic lobules are transferred onto organ culture membranes (Millipore) floating on HF-TOC media. HIV-1 supernatant is added drop-wise to each fragment to initiate the infection. Viral replication is monitored by measuring thymocyte cell associated p24 or virion-associated p24 or RT activity in culture media. Various biological and pharmacological agents can be tested in the cultured media $[18,28,66]$.

B. An HF-TOC fragment after 12 days in culture on the membrane.

C. Relative HIV-1 replication and thymocyte depletion in HF-TOC and SCID-hu Thy/Liv mice. While SCID-hu Thy/Liv mice need 3-6 months to be constructed, HF-TOC can be set up on the day of the infection. HIV-1 (NL4-3) replication peaks at 9-10 days post infection in HF-TOC and at 3 weeks post infection in SCID-hu Thy/Liv mice. HIV-induced thymocyte depletion is detectable at 7 days post infection in HF-TOC and at 2 weeks post infection in SCID-hu Thy/Liv mice. As in SCID-hu Thy/Liv mice, HXB2 fails to replication in HF-TOC [18, 28, 81]. 


\section{A: Direct killing of infected thymocytes}

\section{B: Indirect killing of thymocytes}
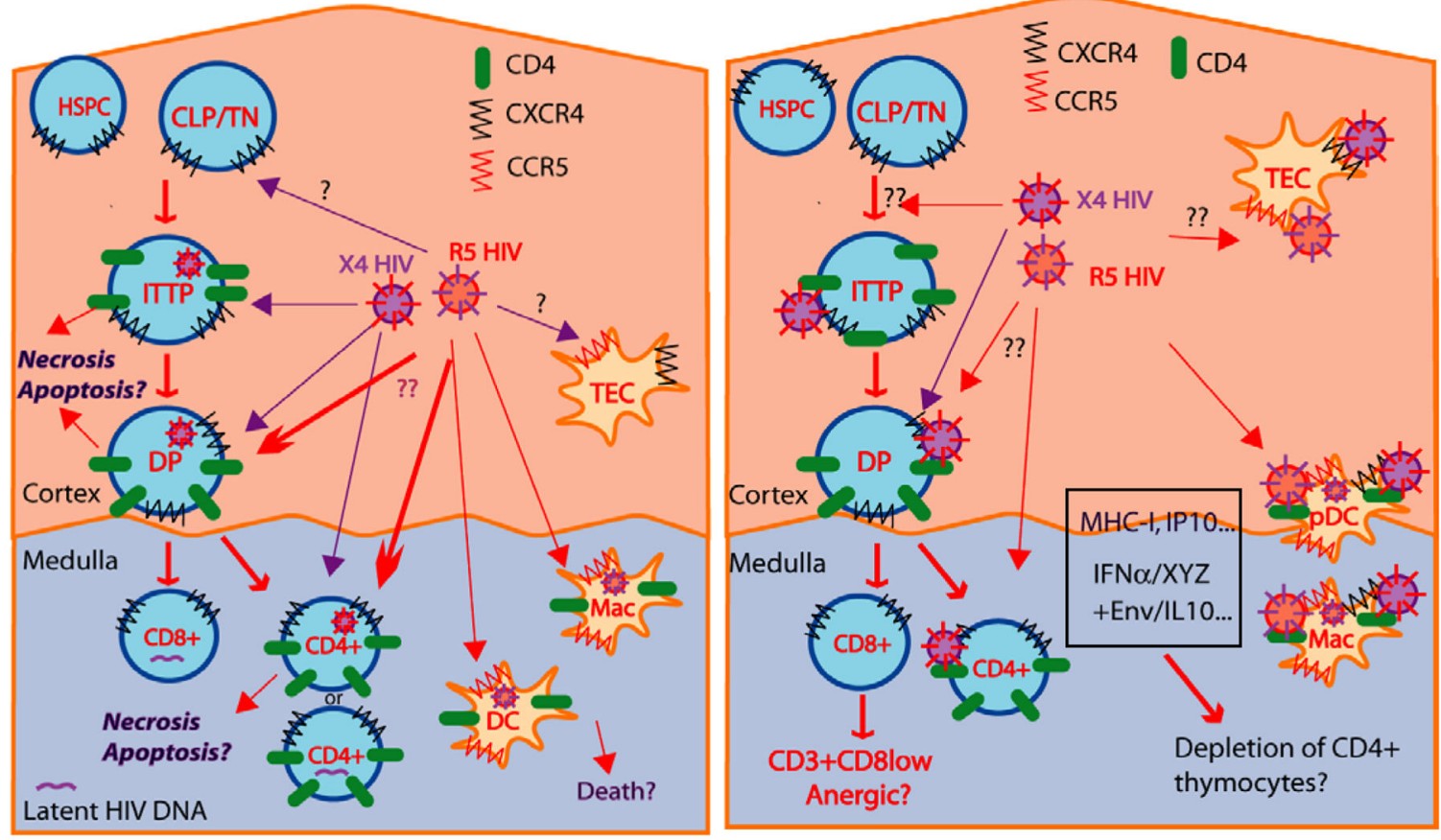

Fig. (2). Direct and indirect mechanisms involved in the depletion of thymocytes

A. Direct infection of CD4+ thymocytes and progenitor cells by HIV-1. Thymocytes expressing CD4 and CXCR4 are direct target of X4-tropic HIV isolates. Infected thymocytes may die (via necrotic and/or apoptotic pathways) or survive to carry the HIV provirus to their progenies (latent infection in mature, resting SP CD4 or CD4 thymocytes). Thymic stromal cells may also be infected and depleted. For R5-tropic isolates, thymic stromal cells and a small number of thymocytes expressing CD4 and CCR5 are first infected. At late stage of infection, CCR5 may be induced on T progenitor cells and thymocytes to allow a second phase of replication in thymocytes.

B. Indirect mechanism of thymocyte depletion. Infection of thymocytes and stromal cells leads to production of viral proteins and host factors, which interact with T progenitor cells and thymocytes to lead to depletion. Viral factors such as env (gp120 or virion-associated gp120-gp41) may interact with CD4 and CXCR4/CCR5 to affect thymocyte survival. Destruction of thymic epithelial cells may also contribute to thymocyte maturation and selection. In addition, host cytokines such as IFNa, IL10 and IP10 are induced directly or indirectly after HIV infection in the thymus. MHC class I induction on thymocytes may affect their survival and maturation, as illustrated by the generation of CD8lowCD3+ mature thymocytes [52, 53, 66, 81]. In the presence of viral proteins, host cytokines and altered stromal cells, thymocytes with high levels of MHCI may be induced to die via apoptosis, necrosis, or aponecrosis mechanisms. 